\title{
Ferulic Acid in Foods: An Overview
}

\author{
Youssef, M.M., Abou-Gharbia, H.A. \& Abou-Farrag, H.T.
}

Food Science and Technology Dept., Fac. of Agric., El-Shatby, Alexandria Univ., 21545, Alexandria, Egypt

Received: 23 October, 2012

Revised: 5 December, 2012

Accepted: 23 December, 2012

\begin{abstract}
Ferulic acid (4-hydroxy-3-methoxycinnamic acid) is a ubiquitous phenolic compound in plant tissues and constitutes a bioactive ingredient in many foods. It is an abundant dietary antioxidant which may offer beneficial effects against cancer, cardiovascular diseases, diabetes and Alzheimer's disease.

In addition to the capability of utilizing ferulic acid as a potent antioxidant, it can be used in vanillin production via biotechnology along with its incorporation in the formulation of edible film packages.

This overview summarizes occurrence, chemistry, analysis, functions along with some examples of the utilization of ferulic acid in food industries.
\end{abstract}

Keywords: Ferulic acid, occurrence, chemistry, analysis, functions, antioxidant, cholesterol, anticancer, vanillin, edible film packages.

\section{INTRODUCTION}

Ferulic acid is one of the major phenolic compounds found in many crop by-products such as wheat bran $(0.5 \%)$, sugar-beet pulp $(0.9 \%)$ and corn kernel (5\%) (Mathew \& Abraham, 2004, Barberousse et al., 2008). Extraction of ferulic acid from some agricultural crop residues is important from the economical point of view, e.g. development of value-added products from renewable by-products.

Ferulic acid exhibits beneficial physiological effects such as antioxidant, antimicrobial, antithrombosis and anti-cancer activities. Consequently, ferulic acid is widely used in food, pharmaceutical and cosmetic industries (Graf, 1992, Ou \& Kwok, 2004, Mateo Anson et al., 2008, Baskaran et al., 2010).

Ferulic acid is cross-linked with lignin and polysaccharides via ester and ether bonds, forming lignin/phenolics-carbohydrate complex in crop residues. Ferulic acid can be released from such a complex with $0.1-0.4 \mathrm{M} \mathrm{NaOH}$ solution at $50-70^{\circ} \mathrm{C}$ (Barberousse et al., 2008). It can also be released enzymatically from plant materials by feruloyl esteroase (Mathew \& Abraham, 2004). Meanwhile, Buranov \& Mazza (2009) described analytical methods for extracting and purification of ferulic acid from flax shives, wheat and corn bran by alkaline hydrolysis and pressurized solvents.

The present overview summarizes occurrence, chemistry, analysis functions and utilization of ferulic acid in the area of food industry.

\section{Chemistry of ferulic acid}

Ferulic acid $\left(\mathrm{C}_{10} \mathrm{H}_{10} \mathrm{O}_{4}\right)$ is 3-(4-hydroxy-3methoxyphenyl)-2-propenoic acid or 4-hydroxy-3methoxycinnamic acid or 3-methoxy-4-hydroxylcinnamic acid (Fig 1).<smiles>COc1cc(C=CC(=O)O)ccc1O</smiles>

Fig. 1: Chemical structure of ferulic acid

Ferulic acid is one of the intermediate compounds that is produced during the biosynthesis of lignin in plants from amino acids (phenylalanine and tyrosine). Notwithstanding, ferulic acid can be cross-linked with lignin and polysaccharides via ester and ether bonds (Barberousse et al., 2008).

Furlic acid in plants tissues presents in two forms: free and conjugated. The percentage of free ferulic acid in vegetables and fruits accounts for $50-90 \%$ of total ferulic acid. As for cereals, free ferulic acid only accounts for $0.1-0.05 \%$ of the total ferulic acid (Zhao \& Moghadsian, 2008).

\section{Occurrence of ferulic acid}

In their review article, Zhao \& Moghadsian 
(2008) tabulated extensive data on the levels of ferulic acid in grains, fruits, vegetables and commercial foods. Grains vary in their ferulic-acid content being in a range of 33 (oat/ bran) to $3300 \mathrm{mg} / 100 \mathrm{~g}$ (refined-corn bran). As for fruits, ferulic acid content ranges from 0.27 (apples) to $11.6 \mathrm{mg} / 100 \mathrm{~g}$ (grapefruit). Vegetables contain ferulic acid in a range from 1.1 (avocado) to $243.6 \mathrm{mg} / 100 \mathrm{~g}$ (bamboo shoots). On the other hand, commercial foods and beverages vary dramatically in their ferulic acid content from 0.24 (beer) to $800 \mathrm{mg} / 100 \mathrm{~g}$ (sugar-beet pulp).

According to Anson et al. (2009), the bioavailability of ferulic acid has been addressed in several studies with variable results from low to high bioavailability (0.4-98\%) depending on the food source. For instance, cereal products, particularly bran, exhibit low availability (3\% in human). On the other hand, bioavailability of ferulic acid in tomato amounted to 25\% (Bourne \& Rice-Evans, 1998) and $28 \%$ in bread (Hader et al., 2004). The binding of ferulic acid to polysaccharides may limits its biovavavilability (Anson et al., 2009).

\section{Analysis of ferulic acid}

Buranov \& Mazza (2009) used pressurized solvents to extract ferulic acid. Pressurised lowpolarity water (PLPW) extraction, also known as sub-critical water extraction, modifies the properties of water by heating above $100^{\circ} \mathrm{C}$ and keeping the pressure sufficiently high to maintain water in a liquid state and thus improves its extraction capability. The PLPW extraction has been compared and reported to be superior to conventional extraction techniques, due to its higher selectivity, cleanliness, speed and cost saving in terms of material and energy consumption (Cacace \& Mazza, 2006, Kim \& Mazza, 2006).

Two methods were applied for ferulic acid extraction. These methods include non-pressurised alkaline hydrolysis $(0.5 \mathrm{M} \mathrm{NaOH})$ and pressurized solvents $(0.5 \mathrm{M} \mathrm{NaOH}$, water, ethanol and ammonia). No differences could be traced between the two methods yielding mostly ferulic acid, $p$ - coumaric acid and small amounts of vanillin (Buranov \& Mazza, 2009).

Purification of ferulic acid from alkaline extracts is greatly simplified by exploiting its solubility. The brown alkaline extracts, which were primarily waxes, can be easily precipitated with $30 \%$ aqueous ethanol and therefore, the commercial production of ferulic acid from crop by-products seems feasible (Buranov \& Mazza, 2009).

Ferulic cid can be quantified via a HPLC-DAD system using Beckman ultra phere $4.6 \mathrm{~mm} \times 250$ $\mathrm{mm}$ ODS colomn (Particle diameter $=5 \mu \mathrm{m}$ ) according to the procedure described by DiGioia et al. (2009).

\section{Functions of ferulic acid}

\section{Antioxidant potency}

Ferulic acid is an abundant dietary antioxidant which may offer beneficial effects against cancer, cardiovascular diseases diabetes and Alzheimer's disease (Zhao \& Moghadasion, 2008). Ferulic acid, due to its phenolic nucleus and unsatuarated side chain, readily forms a resonance stabilized phenoxy radical which accounts for its potent antioxidant activity (Graff, 1992).

Ferulic acid and esterified ferulic acids were added to soybean oil (SBO) and evaluated for oxidative stability and frying stability (Warner \& Laszlo, 2005). Additives included ferulated monacyl glycerol and diacyl glycerol (FMG/ FDG), ferluic acid, ethyl ferulate along with tertiary butyl hydroquinone (TBHQ). After frying tests with potato chips, oils were analyzed for retention of additives and polar compounds. Frying oils with ethyl ferulate or TBHQ produced significantly less polar compounds than SBO with no additives. Potato chips fried in SBO with TBHQ or ferulic acid had significantly lower amounts of hexanol and significantly less rancid odour after 8 days of storage at $60^{\circ} \mathrm{C}$ than other samples. FMG/FDG inhibites deterioration of oil at $60^{\circ} \mathrm{C}$ : Ferulic acid acted as an antioxidant in aged fried food, whereas, ethyl ferulate inhibited the formation of polar compounds in frying oil.

\section{Cholesterol lowering action}

There is currently a great deal of interest in the health benefits of the phytochemicals, polyphenolic flavonoids, and phenyl propanoids through their potential antioxidant, anti-inflammatory and antiaggregatory. According to Castelluccio et al. (1996), the hydroxycinnamates, intermediates in the phenylproanoid synthetic pathway, are effective in enhancing the resistance of low-density lipoprotein (LDL) to oxidation in the order: Caffeic acid $>$ ferulic acid $>p$-coumaric acid. It was obvious that ferulic acid does not associate with the lipid portion of the LDL particles, suggesting that 
it exerts its antioxidant properties from the aqueous phase. Such a finding is of particular interest since the results demonstrate that ferulic acid is more effective antioxidant against LDL oxidation than ascorbic acid as a hydrophilic antioxidant.

Oryzonal is a class of nonsaponifiable lipids of rice bran oil (RBO). More specifically, oryzonal is a group of ferulic acid esters of triterpeny alcohol and plantsterols. Rong et al. (1997) found that oryzonal is at least partially responsible for the cholesterol-lowering action of RBO. In addition, the cholesterol-lowering action of oryzanol was associated with significant reduction in aortic fatty streak formation in hamsters.

\section{Binding of peanut allergens}

Ferulic acid is known to complex with proteins and peanut allergens. Preliminary studies carried out by Chung \& Champagne (2011) indicated that ferulic acid could also be completed with and inhibits $\operatorname{IgE}$ antibodies to peanut allergens in ELISA.

Ferulic acid, at various concentrations $(0-10 \mathrm{mg} /$ $\mathrm{ml}$ ), was mixed with a pooled plasma (containing IgE antibodies) peanut-allergic individuals before incubation with a peanut allergen-bound membrane and colorimetric detection of IgE. Results showed that an enhancement of allergn bands or IgE binding compared to the control, was observed at a ferulic concentration of $10 \mathrm{mg} / \mathrm{ml}$, the point of interest is that, compounds with a similar structure, such as caffeic and chlorogenic acids at the same concentration did not have an enhancing effect on IgE binding (Chung \& Champagne, 2011).

\section{Anti cancer effect}

The chemopreventive efficacy of ferulic acid in orals and skin carcinogensis was demonstrated (Balakrishnan et al., 2008, Nyaradzo et al., 2009, Alias et al., 2009). Moreover, Baskaran et al. (2010) investigated the chemopreventive potential of ferulic acid in 7, 12-dimethylbenz $[\alpha]$ anthracene (DMBA)induced mammary carcinogenesis in Sprague-Dawley rats.

The chemopreventive potential of ferulic acid was assessed by monitoring the tumor incidences, as well as analyzing the status of biochemical (enzymatic and non-enzymatic antioxidants and phase II detoxification enzymes) and molecular (P53 and bcl-2) markers during DMBA-induced mammory carcinogensis. Oral administration of ferulic acid at a dose of $40 \mathrm{mg} / \mathrm{kg}$ body weight to rats treated with DMBA significantly protected the biochemical and molecular abnormalities in DMBA-treated rats. Although the exact mechanism of ferulic acid in this respect is unclear, its antigenotoxic and antioxidant potential as well as modulatory effect on phase II detoxification cascade could play a possible role.

\section{Use of ferulic acid}

In addition to antioxidant potency of ferulic acid as mentioned previously, it can be used also in production of vanillin and formulation of edible film packages. Furthermore, there are numerous pharmaceutical use of ferulic acid.

\section{Production of vanillin}

Nowadays, there is an interest in natural healthy food. Such an interest had an impact on the flavour-producing industries, as the majority of today's flavour needs to be natural (Krings \& Berger, 1998).

Vanillin is one of the most important flavours in the food industry and there is a great interest in its production via biotechnology processes starting from natural substrates such as ferulic acid (DiGioia et al., 2011).

According to Topakas et al. (2003), Sporotrichum thermophile is capable of promoting the formation of vanillic acid during ferulic acid degradation. Ferulic acid metabolism by $S$. thermophile apparently occurred via the propenoic chain degradation and the formation of 4-hydroxyl-3- methoxy styrene (4-vinyl guaiacol) was observed which presumably metabolized to vanillic acid. Under optimum conditions, vanillic acid production from ferulic acid by $S$. thermophile attained very high levels of $4798 \mathrm{mg} / \mathrm{L}$ with a molar yield of $35 \%$.

Cultures of Streptomyces sannanensis MTCC 6637 when grown on minimal medium containing ferulic acid as a sole carbon source, vanillic acid accumulation was observed in the medium as the major biotrons formed product along with transient formation of vanillin. A maximum amount of 400 $\mathrm{mg} / \mathrm{L}$ vanillic acid accumulation was observed, when cultures were grown on $5 \mathrm{mM}$ ferulic acid at $28^{\circ} \mathrm{C}$. This accumulation of vanillic acid was found to be stable in the culture media for a long period (Ghosh et al., 2007).

Among bacteria, recombinant Escherichia coli strains are the most efficient vanillin producers, where Pseudomonas spp. strains although possessing a broader metabolic versatility, rapidly metabolize various phenolic compounds including 
vanillin. In ordrer to develop a robust Pseudomnas fluorescens BF13 strain was inactivated via targeted mutagenesis. Data demonstrated that engineered derivatives of strain BF13 accumulate vanillin if inactivation is associated with concurrent expression of structural genes for feruloyl-CoA synthetase and hydratase/ aldolase, from a low-copy plasmide. The conversion of ferulic acid to vanillin was enhanced by optimization of growth conditions, growth phase and parameters of the bioconversion process. The developed strain produced up to $8.41 \mathrm{~m} \mu$ vanillin, which is the highest final titer of vanillin produced by a Pseudomonas strain to date and opens new perspectives in the use of bacterial biocatalysts for biotechnological production of vanillin from agroindustrial wastes which contain ferulic acid (DiGioia et al., 2011).

\section{Formulation of edible film packages}

Packaging is a necessary step for preservaing the organoleptic, nutritional and hygienic characteristics of food during storage and handling. According to Tharanathan (2003), constant progress in the technology of synthetic film preparation has expanded and supported their utilization in food industry. However, most synthetic films are petrochemicalbased and non-biodegradable, leading to environmental pollution and serious ecological problems.

Contrary to synthetic films, edible films use renewable resources as raw materials and are biodegradable, making them more compatible with the environment. Additionally, other adjuncts such as antimicrobials, antioxidants, nutrients, colourants are easier to be added to edible films, thus further enhancing their protective functions (Ou et al., 2005).

Ferulic acid has been used in formulating edible film package. The following are examples of such films:

\section{Soy protein isolate-ferulic acid films}

Ou et al. (2005) investigated the role of ferulic acid in preparing edible films from soy protein isolate. Data revealed that an optimal concentration of ferulic acid $(100 \mathrm{mg} / 100 \mathrm{~g})$ increased the tensile strength elongation percentage at break and antioxidant activity of films for preservation of fresh lard. Moreover, the properties of the film were further improved when ferulic acid was oxidized by hydrogen peroxide.

A possible mechanism for the role of ferulic acid in the preparation of soy protein isolate-based films is that reacted with amino acids and increased cross-linking of the protein. The point of interest is that the absorbance wave length for ferulic acidprotein (or amino acids) is much longer than ferulic acid or protein (or amino acids) alone. The absorbance shift indicates the formation of a ferulic acidprotein cross-link that may enhance the shelf life of foods by decreasing oxygen permeability (Ou et al., 2004, Ou et al., 2005).

\section{Gelatin-ferulic acid films}

Gelatin film, as most protein films, does not have ideal mechanical properties and water vapour barrier, which limited its application as edible film and biomaterial. Chemical and physical treatments can be applied to modify the polymer network through cross linking of the polymer chains to improve protein film functionality (Chambi \& Grosso, 2006).

Gelatin films were cross-linked by ferulic acid. The maximal mechanical strength of gelatin film could be obtained when the $\mathrm{pH}$ value of filmforming solution was 7 . It was clear that ferulic acid could decrease swelling ratios of the films but there were no obvious effects on water vapour permeability. Moreover, storage for 90 days had little effect on ferulic acid modified films (Cao et al., 2007).

\section{Starch-chitosan blend-ferulic acid films}

Mathew \& Abraham (2008) evaluated the characteristics of ferulic acid incorporated starchchitosan blend edible films. The barrier properties of the blend films were found to improve considerably upon the incorporation of oxidized ferulic acid. Studies on the surface morphology of the control blend films by light microscopy, scanning electron microscopy (SEM) and atomic force microscopy (AFM) revealed a relatively smooth and homgenous nature for the films. However, ferulic acid incoporated films at higher concentrations exhibited phase separation as visualized in the AFM image. At the optimal concentration of ferulic acid $(75 \mathrm{mg} /$ $100 \mathrm{~g}$ of blend solution), a tensile strength of 62.71 MPa and a percentage elongation of $21.6 \%$ were observed. The X-ray diffraction studies indicated that the blend and ferulic acid incorporated films had good miscibility of the components. Moreover, the fourier transform infrared (FT-IR) studies revealed intermolecular interaction among the different components. Also, the ferulic acid incorporated films were also found to reduce the lipid peroxide formation. 


\section{REFERENCES}

Alias, L.M., Manoharan, S., Vellaichany, L., Balakrishnan, S. \& Ramachandran, C.R. 2009. Protective effect of ferulic on 7, 12-dimethylbenz $[\alpha]$ anthracene induced skin carcinogenesis in Swiss albino mice. Experimental and Toxicological Pathology, 61: 205-214.

Anson, N.M., van den Berg, R., Havenaar, R., Bast, A. \& Haenena, G.R.M.M. 2009. Bioavailaibility of ferulic acid is determined by its bioaccessibility. Journal of Cereal Science, 49: 296-300

Balakrishnan, S., Menon, V.P. \& Manoharon, S. 2008. Ferulic acid inhibits 7, 12-di-methylbenz $[\alpha]$ anthrane-induced hamster buccal pouch carcinogenesis. Journal of Medical Food, 11: 693-700.

Barberousse, H., Roiseux, O., Robert, C., Paquot, M., Deroanne, C. \& Blecker, C. 2008. Analytical methodologies for quantification of ferulic acid and its oligomers. Journal of the Science of Food and Agriculture, 88: 14941511.

Baskaran, N. Manoharan, S., Balackrishnan, S. \& Pugalendhi, P. 2010. Chemopereventive potential of ferulic acid in 7, 12-dimethylbenz $[\alpha]$ anthracene induced mammary carcinogenesis in Sprague-Dawley rats. European Journal of Pharmacology, 637: 22-29.

Bourne, L.C. \& Rice-Evans, C. 1998. Bioavailability of ferulic acid. Biochemical and Biophysical Research Communications, 253: 222-227.

Buranov, A.U. \& Mazza, G. 2009. Extraction and purification of ferulic acid from flax shives, wheat and cron bran by alkaline hydrolysis and pressuised solvents. Food Chemistry, 115: $1542-1548$.

Cacace, J.E. \& Mazza, G. 2006. Pressurized low polarity water extraction of lignans from whole flaxseed. Journal of Food Engineering, 77: 1087-1095.

Cao, N., Fu, Y. \& He. J. 2007. Mechanical properties of gelatin films cross-linked, respectively, by ferulic acid and tannin acid. Food Hydrocolloids, 21: 575-584.

Castelluccio, C., Bolwell, G.P., Gerrish, C \& RiceEvans, C. 1996. Differential distribution of feruclic acid to the major plasma constituents in relation to its potential as an antioxidant. Biochemical Journal, 316: 691-694.

Chambi, H. \& Grosso. C. 2006. Edible films produced with gelatin and casein cross linked with transglutaminase. Food Research International, 39: 458-466.

Chung, S. \& Champagne, E.T. 2011. Ferulic acid enhances $\operatorname{IgE}$ binding to peanut allergens in Western blots. Food Chemistry, 124: 16391642.

DiGioia, D., Luziatelli, F., Negraoni, A. Ficca, A.G. 2011. Metabolic engineering of Pseudomonas fluorescens for the production of vanillin from ferulic acid. Journal of Biotechnology, 156: 309-316.

DiGioia, D., Sciubba, L., Ruzzi, M., Setti, L. \& Fava, F. 2009. Production of vanillin from wheat bran hydrolyzatas via microbial bioconversion. Journal of Chemical Technology and Biotechnology, 84: 1441-1448.

Ghosh, S. \& Sachan, A. 2007. Microbial transformation of ferulic acid to vanillic acid by Streptomyces sannanensis MTCC 6637. Journal of Industrial Microbiology and Biotechnology, 34: 131-138.

Graf, E. 1992. Antioxidant potential of ferulic acid. Free Radical Biological and Medicine, 13: 435-448.

Harder, H., Tetens, I., Let, M.B. \& Meyer, A.S. 2004. Rye bran bread intake elevates urinary excretion of ferulic acid in humans, but does not affect the susceptibility of LDL to oxidation ex vivo. European Journal of Nutrition, 43: $230-236$.

Kim, J.W. \& Mazza, G. 2006. Optimization of extraction of phenolic compounds from flax shives by pressurized low-polarity water. Journal of Agriculture and Food Chemistry, 54: 7575-7584.

Krings, U. \& Berger, R.G. 1998. Biotechnolgical production of flavours and fragrances. Applied Microbiology and Biotchnology, 49: 1-8.

Mateo Anson, N., Berg, V.D.R., Havenaar, R. Bast, A. \& Hanen, G.R.M.M. 2008. Ferulic acid from aleurone determines the antioxidant potency of wheat grain (Triticum aestivum L.). Journal of Agricultural and Food Chemistry, 56: 5589-5594. 
Mathew, S. \& Abraham, T.E. 2004. Ferulic acid: An antioxidant found naturally in plant cell walls and feruloyl esterases involved in its release and their applications. Critical Reviews in Biotechnology, 24: 59-83.

Mathew, S. \& Abraham, T.E. 2008. Characterisation of ferulic acid incorpoarated starch-chitosan blend films. Food Hydrocolloids, 22: 826-835.

Nyaradzo, T.I., Murefua, C., Sergio, R. \& Burton, S.G. 2009. Lipase catalysed synthesis of esters of ferulic acid with natural compounds and evaluatin of their antioxidant properties. Journal of Molecular Catalysis Bioenzymatic, 56: 277-282.

Ou, S.Y. \& Kwok, K.C. 2004. Ferulic acid pharmaceutical functions, preparation and application in foods. Journal of the Science of Food and Agriculture, 84: 1261-1269.

Ou, S.Y., Wang, Y., Tang, S., Huang, C. \& Jackson, M.G. 2005. Role of ferulic acid in preparing edible films from soy protein isolate. Journal of Food Engineering, 70: 205-210.
Rong, N., Ausman, L.M. \& Nicolosi, R.J. 1997. Oryzanol decreases cholesterol absortion and Aortic fatty streaks in hamsters. Lipids, 32: 303-309.

Tharanathan, R.N. 2003. Biodegradatble films and composite coatings: Past, present and future. Trends in Food Science and Technology, 14: 71-78.

Topakas, E., Kalogeris, E., Dekos, D., Macris, B.J. \& Chrstakopoulos. 2003. Bioconversion of ferulic acid into vanillic acid by the thermophilic fungus Sporotrichum thermophile. Lebnsmittel-Wissenschaft und Technology, 36: $561-565$.

Warner, K. \& Laszlo, J.A. 2005. Addition of ferulica cid, ethyl ferulate, and feruloylated monoacyl- and diacylglycerols to salad oils and frying oils. Journal of the American Oil Chemists Society, 82: 647-652.

Zhao, Z. \& Moghadsian, M.H. 2008. Chemistry, natural sources, dietary intake and pharmacokinetic properties of ferulic acid: A review. Food Chemistry, 109: 691-762.

\footnotetext{
حمض الثريوليك فِ الأغذية : نظرة شاملة

محمد محمود يوسف، هانئ علي حسن أبو غربية، حسن طلال أبو فراج

قسم علوم وتقنية الأغذية- كلية الزراعة - الشاطبي- جامعة الإسكندرية

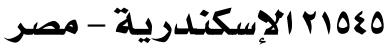

حمض الفريوليك (ع هيدروكسي -r ميثوكسي حامض السنياميك) هو مركب فينولي يتواجد في أنسجة

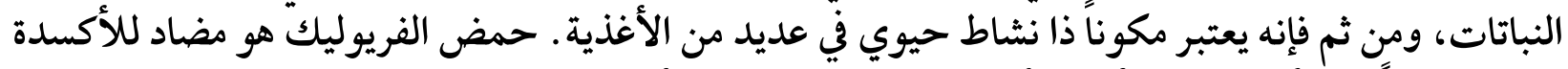

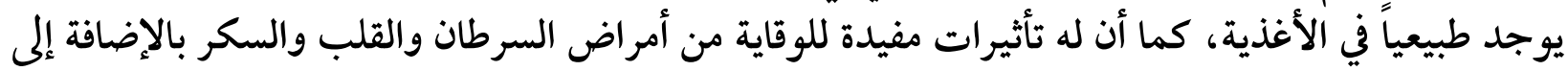

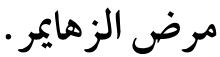

فضلاً عن إمكانية استخدام حمض الفريوليك كمضاد أكسدة فعال، فمن الممكن استخدامه في إنتاج الفانيلين

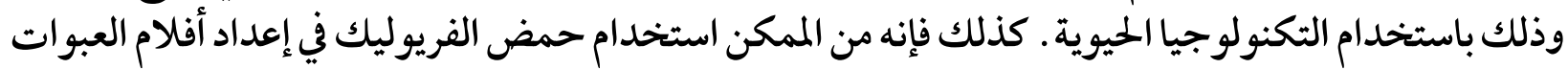

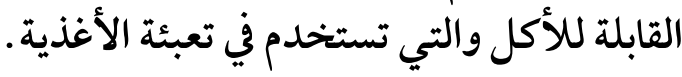

يلخص هذا الاستعر اض، كيمياء وطرق تحليل، والوظائف الحيوية وكذا استخدامات حمض الفريوليك في مجال التصنيع الغذائي.
} 